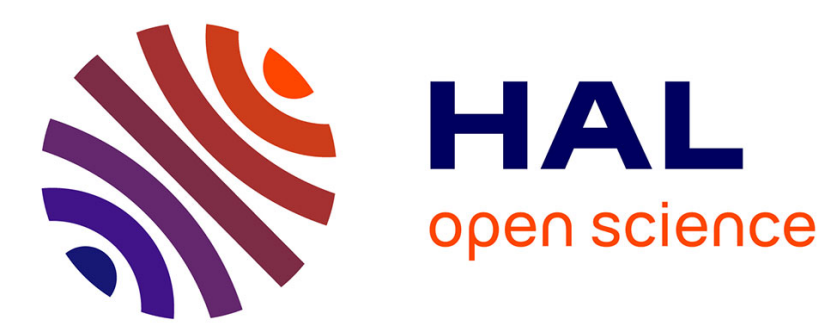

\title{
Availability Optimization of Parallel-Series System by Evolutionary Computation
}

\author{
Mohamed Arezki Mellal, Enrico Zio
}

\section{To cite this version:}

Mohamed Arezki Mellal, Enrico Zio. Availability Optimization of Parallel-Series System by Evolutionary Computation. 2018 3rd International Conference on System Reliability and Safety (ICSRS), Nov 2018, Barcelona, Spain. pp.198-202, 10.1109/ICSRS.2018.8688722 hal-02428549

\section{HAL Id: hal-02428549 https://hal.science/hal-02428549}

Submitted on 19 Mar 2020

HAL is a multi-disciplinary open access archive for the deposit and dissemination of scientific research documents, whether they are published or not. The documents may come from teaching and research institutions in France or abroad, or from public or private research centers.
L'archive ouverte pluridisciplinaire HAL, est destinée au dépôt et à la diffusion de documents scientifiques de niveau recherche, publiés ou non, émanant des établissements d'enseignement et de recherche français ou étrangers, des laboratoires publics ou privés. 


\section{Availability Optimization of Parallel-Series System by Evolutionary Computation}

\author{
Mohamed Arezki Mellal \\ LMSS, Faculty of Engineering Sciences \\ M'Hamed Bougara University \\ Boumerdes, Algeria \\ e-mail: mellal.mohamed@gmail.com, \\ mellal.mohamed@univ-boumerdes.dz
}

\author{
Enrico Zio \\ Chair System Science and the Energy Challenge, \\ Fondation Electricité de France (EDF), CentraleSupélec, \\ Université Paris-Saclay, France \\ Politecnico di Milano, Milan, Italy
}

\begin{abstract}
This paper addresses the problem of availability optimization of a parallel-series system by using evolutionary techniques. Five techniques are considered, namely the cuckoo optimization algorithm, particle swarm optimization, flower pollination algorithm, differential evolution, and genetic algorithms. The integer values and constraints of cost are handled. The results regarding a system with ten subsystems are compared. It demonstrates that the cuckoo optimization algorithm performs best.
\end{abstract}

Keywords-system availability; system cost; parallel-series system; optimization; evolutionary computation

\section{INTRODUCTION}

The availability of systems is crucial for production or service competitiveness. However, increasing the overall system availability comes with a cost. Recently, many works dealing with the optimization of RAMS $+\mathrm{C}$ problems (reliability, availability, maintainability, safety and cost) use evolutionary computation techniques. In [1], [2], the system cost under a fixed availability value has been optimized using the combination of genetic algorithms and Tabu search. The system and cost have been optimized by introducing various techniques, such as artificial immune [3], artificial bee colony [4], genetic algorithms [5], [6], and penalty guided stochastic fractal search [6], [7]. In [8], genetic algorithms have been applied to solve both objectives.

Although evolutionary optimization techniques have been shown to perform well in RAMS+C problems, in practice it can be difficult to decide which one to use. This paper aims to address the availability optimization problem of a parallel-series system. A system with ten subsystems is considered, under the constraints of cost and design. A comparison of five evolutionary computation techniques is offered. Penalty functions are introduced to handle the constraints. The remainder of the paper is organized as follows: Section II describes the problem; Section III presents the numerical case study; Section IV gives a brief description of the implemented evolutionary techniques; Section V gives the results with a discussion; finally, conclusions are given in Section VI.

\section{AVaIlability Optimization OF Parallel-Series SYSTEM}

Design of parallel-series system (Figure 1) can be characterized by the following formulations [1], [2]: System cost
$C_{S}(n, \lambda, \mu)=\sum_{i=1}^{m}\left[\left(\alpha_{i}\left(\lambda_{i}\right)^{-\beta_{i}}+\mu_{i} m c_{i}\right)\left(n_{i}+\exp \left(n_{i} / 4\right)\right)\right]$

where $C_{S}(\bullet)$ is the total system cost, $n_{i}$ is the number of identical redundant components in the $i$ th subsystem, $\lambda_{i}$ is the failure rate of the components in the $i$ th subsystem, and $\mu_{i}$ is the repair rate of the components in the $i$ th subsystem, $m$ is the number of subsystems in the system. $\beta_{i}$ and $\alpha_{i}$ are parameters representing physical features (shaping and scaling factors, respectively) of each component in subsystem $i$.

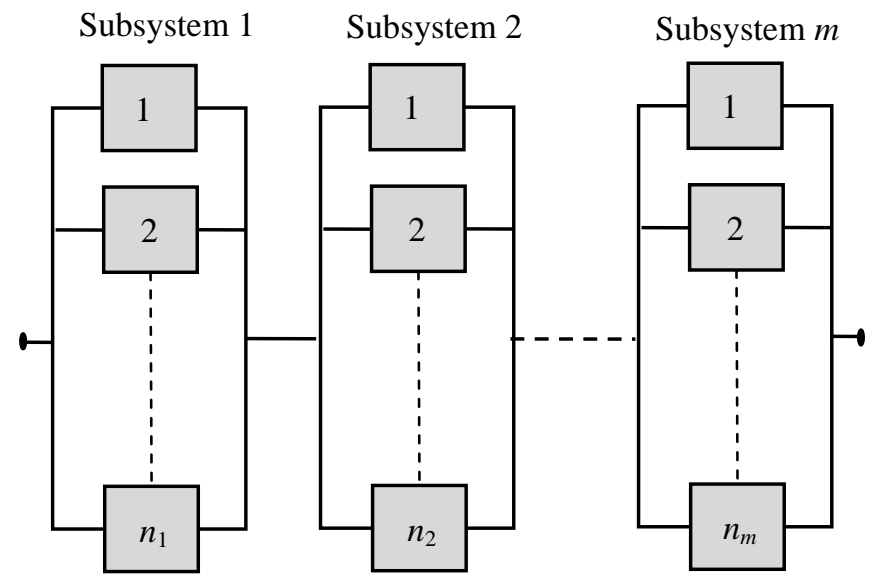

Figure 1. Parallel-series system.

Asymptotic system availability

$$
A_{s}(n, \lambda, \mu)=\prod_{i=1}^{m}\left[1-\left(1-\frac{\mu_{i}}{\lambda_{i}+\mu_{i}}\right)^{n_{i}}\right]
$$

System design configuration constraint of weight

$$
\sum_{i=1}^{m} p_{i}\left(n_{i}\right)^{2} \leq D_{1}
$$

where $p_{i}$ is the product of weight and volume per component in subsystem $i$ and $D_{1}$ is the limit of constraint (3).

System design configuration constraint of the product of weight and volume 


$$
\sum_{i=1}^{m} w_{i} n_{i} \exp \left(n_{i} / 4\right) \leq D_{2}
$$

where $w_{i}$ is the weight of one component in subsystem $i$ and $\mathrm{D}_{2}$ is the limit of constraint (4).

The aim is to allocate the set of values $\left(n_{i}, \lambda_{i}, \mu_{i}\right)$, $i=1,2, \ldots, m$ which satisfies the redundancy allocation in each subsystem of the system. The search for the optimum of (1) (minimum) and (2) (maximum), constrained by (3) and (4), is performed within:

$$
\begin{aligned}
& n_{i} \geq 1 ; n_{i} \in \mathbb{Z}^{+} \\
& \lambda_{i} \in\left[\lambda_{i}^{L}, \lambda_{i}^{U}\right] \subset \mathfrak{R}^{+} \\
& \mu_{i} \in\left[\mu_{i}{ }^{L}, \mu_{i}^{U}\right] \subset \mathfrak{R}^{+}
\end{aligned}
$$

where $\lambda_{i}^{L}, \mu_{i}^{L}, \lambda_{i}{ }^{U}, \mu_{i}{ }^{U}$ are the lower and upper limits of the failure and repair rates, respectively.

\section{NUMERICAL CASE STUDY}

The system considered consists of ten subsystems connected in parallel-series configuration (Figure 1, with $m=10)$. Table I reports the data of the system.

TABLE I. DATA OF THE SYSTEM

\begin{tabular}{|c|c|c|c|c|c|}
\hline Subsystem $\boldsymbol{i}$ & $\boldsymbol{\alpha}_{\boldsymbol{i}} \mathbf{( 1 0}^{\mathbf{5}} \mathbf{)}$ & $\boldsymbol{\beta}_{\boldsymbol{i}}$ & $\boldsymbol{m c}_{\boldsymbol{i}}$ & $\boldsymbol{p}_{\boldsymbol{i}}$ & $\boldsymbol{w}_{\boldsymbol{i}}$ \\
\hline 1 & 1.25 & 1.5 & 500 & 2 & 6 \\
2 & 2.70 & 1.5 & 500 & 4 & 9 \\
3 & 8.10 & 1.5 & 500 & 3 & 7 \\
4 & 4.50 & 1.5 & 500 & 2 & 6 \\
5 & 1.90 & 1.5 & 500 & 4 & 8 \\
6 & 3.55 & 1.5 & 500 & 2 & 5 \\
7 & 2.45 & 1.5 & 500 & 4 & 3 \\
8 & 6.30 & 1.5 & 500 & 3 & 9 \\
9 & 1.80 & 1.5 & 500 & 2 & 7 \\
10 & 5.25 & 1.5 & 500 & 2 & 5 \\
\hline
\end{tabular}

In [1], [2], the authors fixed the system cost as an objective to be minimized in the case of a system with five subsystems. In the present paper, the goal is to maximize the system availability under the constraints of cost and system configurations. Therefore, according to Eqs. (1)-(5) and the data reported in Table I, the problem of this case study is:

$$
\text { Maximize } A_{s}(n, \lambda, \mu)=\prod_{i=1}^{10}\left[1-\left(1-\frac{\mu_{i}}{\lambda_{i}+\mu_{i}}\right)^{n_{i}}\right]
$$

subject to

$$
\sum_{i=1}^{10}\left[\left(\alpha_{i}\left(\lambda_{i}\right)^{-\beta_{i}}+\mu_{i} m c_{i}\right)\left(n_{i}+\exp \left(n_{i} / 4\right)\right)\right] \leq C_{s}^{*}
$$

$$
\begin{gathered}
\sum_{i=1}^{10} p_{i}\left(n_{i}\right)^{2} \leq D_{1} \\
\sum_{i=1}^{10} w_{i} n_{i} \exp \left(n_{i} / 4\right) \leq D_{2}
\end{gathered}
$$

where

$n_{i} \geq 1\left(n_{i} \in \mathbb{Z}^{+}\right)$

$\lambda_{i} \in\left[10^{-7}, 10^{-3}\right] \subset \mathbb{R}^{+}, \mu_{i} \in\left[32 \times 10^{-7}, 32 \times 10^{-3}\right] \subset \mathbb{R}^{+}$

$A_{s} \geq 0.9$

$C_{s} *=250 ; D_{1}=200 ; D_{2}=300$, in arbitrary units.

\begin{tabular}{|c|c|c|}
\hline Methods & Advantages & Limitations \\
\hline GA & Robust, Flexibility & $\begin{array}{c}\text { Premature convergence, } \\
\text { Problem encoding, } \\
\text { Requires high function } \\
\text { evaluations }\end{array}$ \\
\hline $\mathrm{DE}$ & Accurate, Effective, & No proof of convergence \\
\hline PSO & $\begin{array}{c}\text { Fast execution, } \\
\text { Simple calculations }\end{array}$ & $\begin{array}{l}\text { Velocity parameters could } \\
\text { be difficult to hand }\end{array}$ \\
\hline $\mathrm{COA}$ & $\begin{array}{c}\text { Proper convergence, } \\
\text { Simple parameters to } \\
\text { be handled }\end{array}$ & $\begin{array}{c}\text { Hard to handle integer } \\
\text { variables }\end{array}$ \\
\hline FPA & $\begin{array}{l}\text { Good convergence } \\
\text { rate }\end{array}$ & $\begin{array}{l}\text { Parameters could be } \\
\text { difficult to hand }\end{array}$ \\
\hline
\end{tabular}

\section{EVOLUTIONARY COMPUTATION TECHNIQUES}

Five evolutionary computation techniques are applied: genetic algorithms, differential evolution, particle swarm optimization, cuckoo optimization algorithm, and flower pollination algorithm. Table II summarizes their main characteristics.

TABLE II. CHARACTERISTICS OF THE APPLIED TECHNIQUES

The redundancy variables are rounded to the nearest integer values, while the constraints are handled using penalty functions [7], introduced in the formulation of the problem as follows:

$$
\text { Fitness value }=A_{s}(n, \lambda, \mu)+\psi(n, \lambda, \mu)
$$

with the penalty function

$$
\psi(n, \lambda, \mu)=\sum_{h=1}^{M} \phi_{h} \cdot \max \left(0, g_{h}(n, \lambda, \mu)\right)^{2}
$$

where $\phi_{h}$ is the penalty factor and $M$ is the number of constraints $(M=9)$.

\section{A. Genetic Algorithms (GA)}

The GA are based on the principles of the evolution of species [9], [10]. Table III contains the parameters and rules of the implemented GA. 
TABLE III. GENETIC ALGORITHM PARAMETERS AND RULES.

\begin{tabular}{|ll|}
\hline Population size & 20 \\
Selection technique & Standard roulette \\
Mutation probability & $10^{-3}$ \\
Crossover probability & 1 \\
\hline
\end{tabular}

\section{B. Differential Evolution (DE)}

The DE is a population-based algorithm similar to GA, but with more perturbations in the iterations of the population [11]-[13]. Table IV contains the parameters and rules of the implemented DE.

TABLE IV. DIFFERENTIAL EVOLUTION PARAMETERS AND RULES.

\begin{tabular}{|ll|}
\hline Population size & 20 \\
Scaling factor & 0.2 \\
Crossover rate & 0.2 \\
\hline
\end{tabular}

\section{Particle Swarm Optimization (PSO)}

The PSO is based on the behavior of swarms of fishes and birds [14], [15]. Table $\mathrm{V}$ contains the parameters and rules of the implemented PSO.

TABLE V. PARTICle SWARM Optimization PARAMETERS.

\begin{tabular}{|ll|}
\hline Swarm size & 20 \\
Inertia weight & 1 \\
Learning coefficient & 2 \\
\hline
\end{tabular}

\section{Cuckoo Optimzization Algorithm (COA)}

The COA is inspired from the processes of reproduction and migration of the cuckoos birds [16], [17]. Table VI contains the parameters and rules of the implemented COA.

TABLE VI. CUCKOO OPTIMIZATION ALGORITHM PARAMETERS.

\begin{tabular}{|ll|}
\hline Number of cuckoos & 20 \\
Motion coefficient & 5 \\
Radius coefficient & $10^{-3}$ \\
\hline
\end{tabular}

\section{E. Flower Pollination Algorithm (FPA)}

The principles of the FPA is based on the pollination process of flowers [18]. The parameters of the implemented FPA are reported in Table VII.

TABLE VII. FlOWER POLLINATION ALGORITHM PARAMETERS.

\begin{tabular}{|ll|}
\hline Population size & 20 \\
Probability switch & 0.8 \\
\hline
\end{tabular}

The values of the parameters of the above techniques have been fixed based on experience and trial-and-error, in the attempt to get the best performance for each technique. The algorithms have been encoded using MATLAB 2017 and run on a personal computer with the following characteristics: Intel Core I3 of $2.53 \mathrm{GHz}$ with $4 \mathrm{~GB}$ of RAM. The problem involves 30 decision variables, including 10 integer values.

\section{RESULTS AND DISCUSSION}

Table VIII summarizes the worst, average and best values of $A_{s}$ found by each algorithm, whereas Table IX reports the optimal solutions, system cost $C_{s}$, standard deviation (SD) after 10 independent runs, number of function evaluations (NFE) required to find the best solution, and the CPU time.

TABLE VIII. RESULTS.

\begin{tabular}{|c|c|c|c|}
\hline Method & Worst & Average & Best \\
\hline COA & 0.9697 & 0.9734 & $\mathbf{0 . 9 7 6 5}$ \\
GA & 0.9053 & 0.9255 & 0.9589 \\
FPA & 0.9011 & 0.9267 & 0.9644 \\
DE & 0.9015 & 0.9350 & 0.9654 \\
PSO & 0.9240 & 0.9424 & 0.9649 \\
\hline
\end{tabular}

From Table VIII, it can be observed that the best values of $A_{s}$ found by each algorithm are: PSO (0.9649), DE (0.9654), FPA (0.9644), GA (0.9589), and COA (0.9765). Thus, the maximum $A_{s}$ has been found by the COA $\left(A_{s}=0.9765\right)$, whereas the minimum value 0.9589 has been provided by the GA. Furthermore, the worst and average values found by the COA are better. Figure 2 illustrates the best values of $A_{s}$ found by each algorithm.

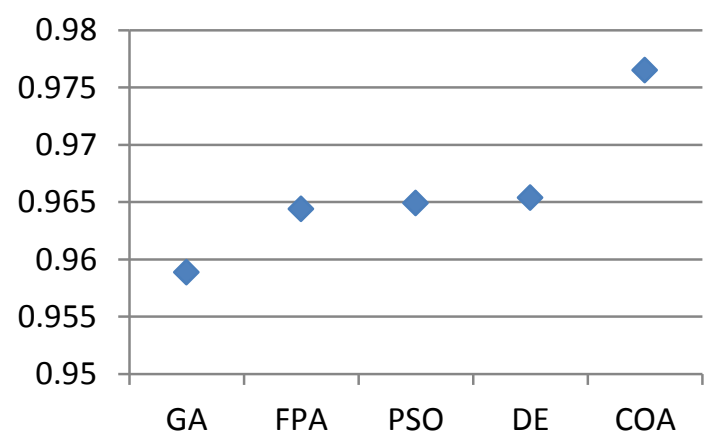

Figure 2. Best system availability provided by each evolutionary computation technique.

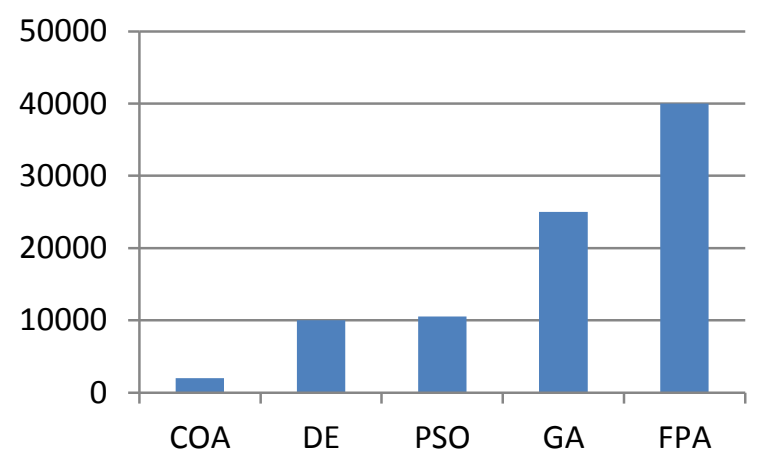

Figure 3. NFE required by each evolutionary computation technique. 
TABLE IX. DETAILED RESULTS.

\begin{tabular}{|c|c|c|c|c|c|c|c|c|}
\hline Method & $n$ & $\lambda\left(10^{-3}\right)$ & $\mu\left(10^{-2}\right)$ & $C_{s}$ & $A_{s}$ & NFE & SD & CPU (s) \\
\hline $\mathrm{COA}$ & $\begin{array}{c}(3,2,2,3,2,2 \\
3,2,3,3)\end{array}$ & $\begin{array}{l}0.5435,0.4903, \\
0.7522,0.8219, \\
0.4606,0.4313, \\
0.6612,0.6649, \\
0.5661,0.8780)\end{array}$ & $\begin{array}{l}(0.4393,0.8895, \\
1.0907,0.5776, \\
0.8726,0.7540, \\
0.4958,1.1125, \\
0.4630,0.6139)\end{array}$ & 249.9922 & 0.9765 & 2,000 & $\overline{0.001884}$ & 1.5912 \\
\hline GA & $\begin{array}{c}(3,3,2,2,3,3 \\
2,2,2,2)\end{array}$ & $\begin{array}{l}(0.5978,0.7117, \\
0.8648,0.6510, \\
0.4545,0.8658, \\
0.5126,0.6194, \\
0.2048,0.7043)\end{array}$ & $\begin{array}{c}(0.3637,0.4170, \\
1.0598,0.9699, \\
0.3067,0.6567, \\
0.8701,0.9023, \\
1.7164,0.9745)\end{array}$ & 248.5754 & 0.9589 & 25,000 & 0.0166 & 1.6536 \\
\hline FPA & $\begin{array}{c}(3,2,2,2,2,2, \\
3,3,3,2)\end{array}$ & $\begin{array}{l}0.5157,0.7579, \\
0.4919,0.6473, \\
0.5591,0.9095, \\
0.4938,0.8977, \\
0.7457,0.6910)\end{array}$ & $\begin{array}{l}0.3410,0.7964, \\
1.0277,0.8878, \\
1.0974,1.4357, \\
0.2876,0.5501, \\
0.4852,0.8708)\end{array}$ & 249.8303 & 0.9644 & 40,000 & 0.0181 & 5.8032 \\
\hline $\mathrm{DE}$ & $\begin{array}{c}(3,2,2,1,2,1, \\
2,3,3,2)\end{array}$ & $\begin{array}{l}(0.4844,0.3590, \\
0.7673,0.4063, \\
0.5366,0.7744, \\
0.6316,0.9290, \\
0.6903,0.5165)\end{array}$ & $\begin{array}{l}0.4681,0.5971, \\
1.1225,1.9211, \\
0.2822,1.1092, \\
0.8182,0.8442, \\
0.8668,0.4274)\end{array}$ & 244.0932 & 0.9654 & 10,000 & 0.0181 & 3.66 \\
\hline PSO & $\begin{array}{c}(2,2,2,2,2,2 \\
3,2,2,2)\end{array}$ & $\begin{array}{l}(0.3515,0.5183, \\
0.7869,0.5934, \\
0.5166,0.5958, \\
0.7610,0.7557, \\
0.5538,0.6736)\end{array}$ & $\begin{array}{l}(0.6501,0.8490, \\
1.0842,0.8974, \\
0.8375,0.9218, \\
0.5122,1.0620, \\
0.8899,0.9773)\end{array}$ & 249.9994 & 0.9649 & 10,500 & 0.0128 & 8.5333 \\
\hline
\end{tabular}

It can be also observed that the COA has required fewer number of function evaluations $(2,000)$, consumed less CPU time $(1.5912 \mathrm{~s})$, and is more stable in term of standard deviation (0.001884) than the other techniques. Figure 3 summarizes the NFE values required by each technique. The above results reveal that the penalty function has been successfully implemented and the COA has outperformed the other applied evolutionary computation techniques.

\section{CONCLUSIONS}

In this paper, the system availability of a parallel-series system has been addressed using five evolutionary computation techniques: genetic algorithm (GA), differential evolution (DE), particle swarm optimization (PSO), flower pollination algorithm (FPA), and the cuckoo optimization algorithm (COA). A case study involving 10 subsystems has been investigated and a penalty function has been implemented for handling the constraints. From the results it can be concluded that the COA has outperformed the other four techniques in terms of system availability, number of function evaluations, standard deviation, and CPU time. On the other hand the integer values of redundancy have been successfully handled in implementing the five techniques. Further works on other system configurations will be performed to confirm the results.

\section{REFERENCES}

[1] G. S. Liu, "Availability optimization for repairable parallel-series system by applying Tabu-GA combination method," in 10th IEEE International Conference on Industrial Informatics, 2012, pp. 803808.

[2] G. S. Liu, "Availability optimization for repairable n-stage standby system by applying Tabu-GA combination method," Int. J. Model. Optim., vol. 3, no. 3, pp. 245-250, 2013.

[3] Y. C. Hsieh and P. S. You, "An effective immune based two-phase approach for the optimal reliability-redundancy allocation problem," Appl. Math. Comput., vol. 218, no. 4, pp. 1297-1307, 2011.

[4] H. Garg, M. Rani, and S. P. Sharma, "An efficient two phase approach for solving reliability-redundancy allocation problem using artificial bee colony technique," Comput. Oper. Res., vol. 40, no. 12, pp. 2961-2969, 2013.

[5] M. A. Mellal and E. J. Williams, "Large scale reliability-redundancy allocation optimization problem using three soft computing methods," in Modeling and Simulation based Analysis in Reliability Engineering, CRC Press Francis \& Taylor, 2018, pp. 199-214.

[6] M. A. Mellal and E. Zio, "System reliability-redundancy allocation by evolutionary computation," in 2017 2nd International Conference on System Reliability and Safety, 2017, pp. 15-19.

[7] M. A. Mellal and E. Zio, "A penalty guided stochastic fractal search approach for system reliability optimization," Reliab. Eng. Syst. Saf., vol. 152, pp. 213-227, 2016.

[8] M. Marseguerra, E. Zio, and S. Martorell, "Basics of genetic algorithms optimization for RAMS applications," Reliab. Eng. Syst. Saf., vol. 91, pp. 977-991, 2006. 
[9] J. H. Holland, Adaptation in Natural and Artificial Systems, vol. Ann Arbor. 1975.

[10] G. Renner and A. Ekart, "Genetic algorithms in computer aided design," Comput. Des., vol. 35, no. 8, pp. 709-726, 2003.

[11] R. Storn and K. Price, "Differential evolution - A simple and efficient adaptive scheme for global optimization over continuous spaces," Berkeley, CA, USA, 1995.

[12] E. Zio, L. R. Golea, and G. Sansavini, "Optimizing protections against cascades in network systems: A modified binary differential evolution algorithm," Reliab. Eng. Syst. Saf., vol. 103, pp. 72-83, 2012.

[13] E. Zio and G. Viadana, "Optimization of the inspection intervals of a safety system in a nuclear power plant by Multi-Objective Differential Evolution (MODE)," Reliab. Eng. Syst. Saf., vol. 96, no. 11, pp. 1552-1563, 2011.
[14] J. Kennedy and R. Eberhart, "Particle swarm optimization," Neural Networks, 1995. Proceedings., IEEE Int. Conf., vol. 4, pp. 1942-1948 vol.4, 1995.

[15] M. A. Mellal and E. J. Williams, "A survey on ant colony optimization, particle swarm optimization, and cuckoo algorithms," in Handbook of Research on Emergent Applications of Optimization Algorithms, IGI Global., USA, 2018.

[16] R. Rajabioun, "Cuckoo optimization algorithm," Appl. Soft Comput., vol. 11, no. 8, pp. 5508-5518, 2011.

[17] M. A. Mellal and E. J. Williams, "The cuckoo optimization algorithm and its applications," in Handbook of Neural Computation, Elsevier., 2017, pp. 269-277.

[18] X.-S. Yang, "Flower pollination algorithm for global optimization," Unconv. Comput. Nat. Comput., vol. 7445, pp. 240-249, 2012. 